\title{
SULPHONAMIDES IN GONORRHOEA
}

\author{
By W. K. FITCH \\ Editor, The Pharmaceutical Journal
}

It is a rare occurrence in peace-time for any of the official bodies to make specific recommendations in respect of the treatment of disease. Usually a line of attack on an epidemic or on a condition which is particularly prevalent is built up gradually, and is as much the outcome of teaching in the medical school combined with experience in the hospital, as it is due to any carefully planned investigations sponsored by a government department or any other official organization. Gradually, however, the exigencies of the war have shown that in time of an emergency it is necessary to adopt different measures; the lessons are being slowly learned. Thus the treatment of venereal disease by the sulphonamide compounds can be cited as an example of the way in which the individual practitioner is being directed and assisted by officially appointed guides. It is as well that this advice has been available and that impartial judges have been able to choose, out of the dozen or so sulphonamide compounds which have been used in clinical practice, those that offer the greatest possibilities in the treatment of gonorrhoea. The recently issued Medical Research Council War Memorandum No. 10 (The Medical Use of Sulphonamides) and Notices to Ships' Masters published by the Ministry of War Transport make it clear that sulphathiazole and sulphadiazine are considered to be superior to other related compounds in the treatment of this condition.

The parent substance of the majority of sulphonamides is sulphanilamide, a chemical compound, which although first synthesized by Gelmo in 1908 had no. other use than in the German dye industry until after Domagk (1935) reported that he had been able to prevent the development of streptococcal septicaemia in mice by giving them an azo dye containing this structure. The dye was sulphonamidocrysoidin (4-sulphonamido-2' : 4'-diaminoazobenzene) and its activity, as the Tréfouëls, Nitti and Bovet (1935) showed, is due to the free sulphanilamide liberated in the body from the azo dye. Once this theory had been postulated and its accuracy confirmed research on the synthesis of derivatives began in earnest. Sulphanilamide itself is made by acting on acetanilide with chlorosulphonic acid, producing a chlorosulphone, which when treated with ammonia yields the amide of acetylsulphanilic acid. The acetyl radical is removed by hydrochloric acid and the resulting hydrochloride converted into sulphanilamide by treating with alkali.

From the following table, which includes the structures of the more familiar sulphonamides used in clinical medicine, may be seen the relation between sulphanilamide and the other compounds.

It will be observed that in the synthesis of these compounds the theory of noninterference with the sulphanilamide portion of the molecule in order to preserve the streptococcidal action of the compound has been accepted. With sulphacetamide the sulphonamide grouping is acetylated, whereas with sulphapyridine, sulphathiazole, sulphadiazine, sulphamethazine and sulphamerazine, the reaction is simply one of substitution with a pyridine, thiazole, pyrimidine, dimethylpyrimidine or methylpyrimidine radical respectively. Although the general processes of manufacture of the sulphonamides are patented and the patents are of course open to inspection, details of the actual methods used are secrets carefully guarded by the makers, but an indication of the immensity of the task of preparing large quantities of a single derivative, sulphadiazine, has recently been disclosed by Northey of the Calco Chemical Division of the American Cyanamide Company (1943). A short summary of the method adopted will show a little of the elaborate work involved when it is decided to produce any of these compounds on a large scale.

As the result of laboratory research, in the course of which one pound of sulphadiazine costing several thousands of dollars was produced, a method was developed for making a necessary intermediate compound, 2-amino-4-hydroxypyrimidine, starting with malic acid 
and sulphuric acid ; the formylacetic acid thus formed was converted into guanidine and thence to isocytosine acid sulphate which on neutralization with ammonia yielded isocytosine (2-amino-4-hydroxypyrimidine). So far so good; construction of the sulphadiazine plant was based on this process. When the plant had-been partly erected the sole supplier of malic acid reported a failure of the autoclave used in its synthesis; as replacement of this apparatus which was made of a special alloy on high priority was out of the question for many months, a fresh method of synthesizing the intermediate had to be devised. The process adopted depended upon reacting together ethyl formate, sodium ethylate and ethyl acetate to form sodium formylacetic ester, followed by its conversion into sodium isocytosine, subsequent reaction with phosphorus oxychloride to form 2-amino-4-chloropyrimidine and the replacement of the chlorine with hydrogen by catalytic reduction to give 2-aminopyrimidine. The final stage was to convert the 2-aminopyrimidine by reaction with acetylsulphanilyl chloride in dry pyridine, followed by hydrolysis with sodium hydroxide, to sulphadiazine. As will be seen the story of this synthesis is mainly based on the production of the substituent, the pyrimidine part of the molecule; it has been told in some detail in order to show a few of the difficulties the manufacturer encounters when he attempts to convert small-scale laboratory methods to the requirements of large-scale factory production, in which naturally the yield is proportionately much smaller than that obtained in experimental plants.

TABLE 1

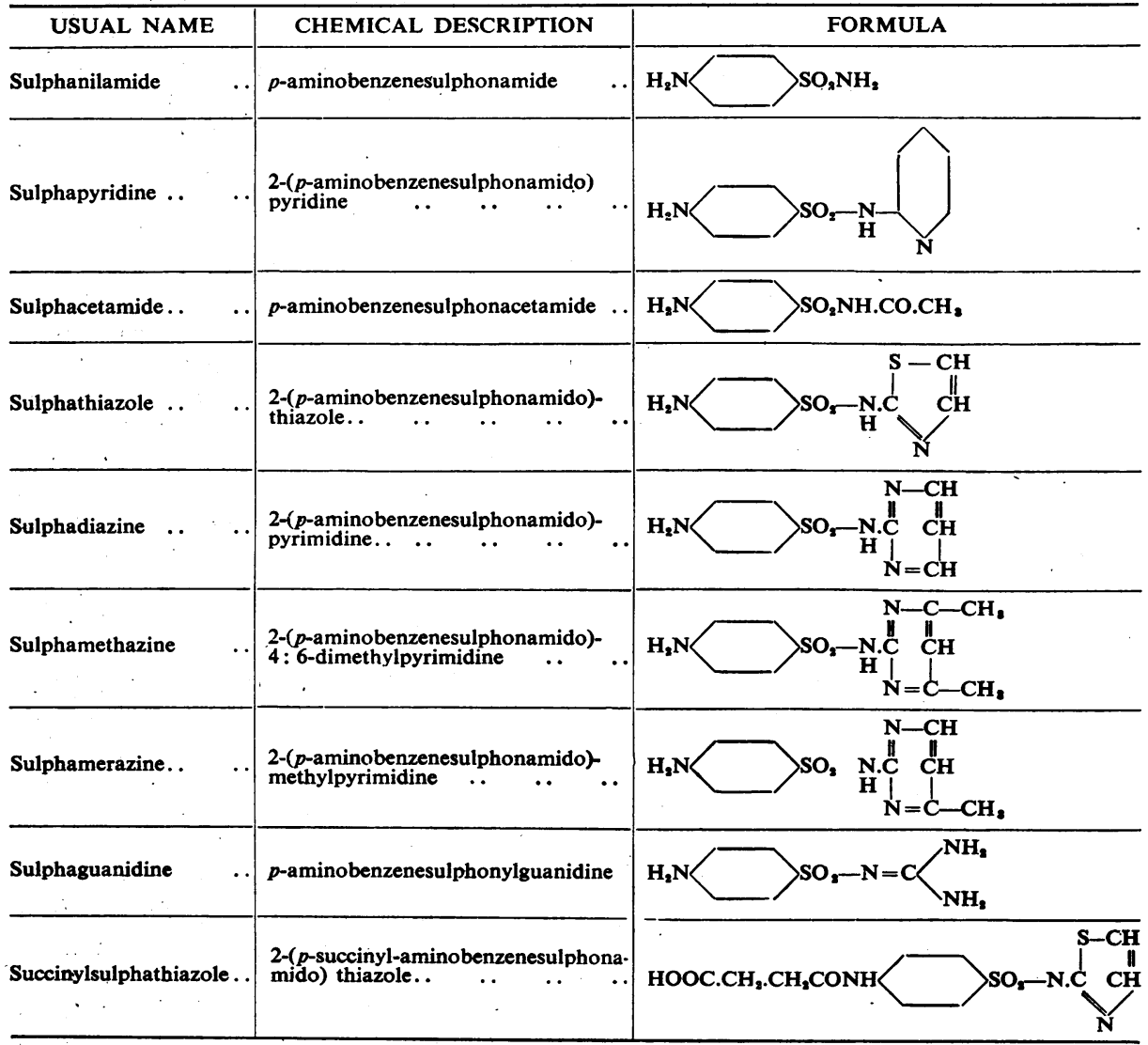

Before going on to discuss some practical methods of administration it may be worth while considering the action of the sulphonamide compound in the body. Although few would agree that the exact method by which sulphathiazole, for example, acts on the gonococcus, is known, the concensus of opinion is that the theory put forward by Fildes (1940) and others, that these compounds upset the enzyme systems which are essential for the reproduction of the bacteria by replacing the $p$-aminobenzoic acid that is so necessary. for their growth, is right. Conversely $p$-aminobenzoic acid has a marked antisulphonamide effect and it has 
been shown by Wyss, Strandskov and Schmelkes (1942) that in vitro the molecule of $p$-aminobenzoic acid will inhibit the action of 3,300 molecules of sulphanilamide, using $E$. coli. Associated with this theory is a much more complex one, put forward by Bell and Roblin (1942), based on physico-chemical and molecular considerations. In the simple way in which it has been expressed by Northey it means that the most active sulphonamide derivatives are those which approach most closely to the molecular structure and state of distribution of electric charge of the p-aminobenzoate ion. Through the use of this theory it is possible to predict with some certainty the activities of new sulphonamide derivatives before they have been synthesized.

\section{Solubility and hydrogen ion concentration}

Carefully determined data on the physical constants of the sulphonamides, so essential for an accurate understanding of the fate of the compounds in the body, are not readily available, so many observers having been content to accept the figures recorded by other workers. It is therefore worth while setting out in the table below the solubility and hydrogen ion concentration of the more commonly used sulphonamides as determined in carefully controlled conditions by Clark, Strakosch and Levitan (1942) at temperatures of $25^{\circ} \mathrm{C}$. $\left(77^{\circ} \mathrm{F}\right.$.) and $37^{\circ} \mathrm{C}$. (98.6 ${ }^{\circ} \mathrm{F}$.).

In nearly every instance the solubility of the conjugated form (usually the acetylated compound) is much less, and in consequence trouble frequently arises through the deposition of the acetyl derivative in the urinary passages. Some mitigation of the condition can be effected by giving alkali and, especially in summer weather, increasing even the large fluid intake which is always necessary when sulphonamides are administered by the mouth.

\section{Sulphathiazole}

It has been asserted that no matter what sulphonamide is used in gonorrhoea it will effect one of three things: (1) it may produce a true cure with remarkable promptitude.; (2) it may produce an apparent cure in some patients who become asymptomatic carriers ; or (3) it may fail to produce any effect whatever. Several attempts have been made to determine the relative values of the sulphonamides in the treatment of gonorrhoea and as already stated it has been found that the most satisfactory results are obtained with sulphadiazine or sulphathiazole, although many venerologists report that cures can be effected with equal certainty by treatment with sulphapyridine. Nevertheless, the two former compounds are generally accepted as specific, the evidence being based on a large number of trials and supported by such official recommendations as those contained in the amendments to the Ship Captain's Medical Guide in which the dose has been fixed at six 0.5 gramme tablets each night and morning for five consecutive days. In America Douglas, Davis and Shandorf (1942) observed the effect of treating 185 patients, 64 with sulphanilamide, 62 with sulphathiazole, and 59 with sulphadiazine. The most commonly employed daily dosage was 5.4 grammes of sulphanilamide, 6 grammes of sulphathiazole and 4 grammes of sulphadiazine, with a total dosage amounting to 36 grammes for sulphanilamide, 40 grammes for sulphathiazole and 20-29 grammes for sulphadiazine. The optimum results were obtained with 4 grammes of sulphadiazine or sulphathiazole in divided daily doses for six consecutive days. A comparison of the value of sulphapyridine, sulphathiazole and sulphadiazine in gonorrhoea has been made by La Towsky, Knight, Uhle and Baker (1942). They found that the average doses of sulphonamides needed to effect a cure were as follows. Of sulphapyridine, 23.5 grammes were required, of sulphathiazole, 28 grammes and of sulphadiazine, 17.5 grammes ; the treatment period in each case was eight days. Of equal significance is their report that 75 per cent of the patients treated with sulphapyridine complained of intolerance, compared with 11.5 per cent who had sulphathiazole and only 8.8 per cent who. received sulphadiazine. Confirmation of the value of sulphathiazole in uncomplicated cases is provided by Jefferiss and McElligott (1943) who treated 567 cases in a R.A.F. hospital. A success rate of 89.5 per cent was achieved with a course 
of 6 grammes a day for two days, the sulphathiazole being given every four hours, night and day, in order that the blood concentration might be kept at a continuous high level.

\section{Sulphathiazoline}

A variation of sulphathiazole, which in the hands of Leberman and Alexander (1943), has shown considerable promise in the treatment of gonorrhoea, is sulphathiazoline (2-sulphanilyl-3:5-dihydrothiazole), a derivative of sulphanilamide in which an amide nitrogen has been replaced by a heterocyclic nucleus containing a

TABLE 2

\begin{tabular}{|c|c|c|c|c|c|c|c|}
\hline \multirow{2}{*}{\multicolumn{3}{|c|}{ COMPOUND }} & \multicolumn{3}{|c|}{$25^{\circ} \mathrm{C}$} & \multicolumn{2}{|c|}{$37^{\circ} \mathrm{C}$. } \\
\hline & & & \multirow{2}{*}{$\begin{array}{c}\text { WATER } \\
0.836\end{array}$} & \multirow{2}{*}{$\frac{\begin{array}{c}\text { HUMAN } \\
\text { SERUM }\end{array}}{0.981}$} & \multirow{2}{*}{$\frac{p H}{7 \cdot 15}$} & \multirow{2}{*}{$\frac{\text { WATER }}{1.460}$} & \multirow{2}{*}{$\begin{array}{c}\begin{array}{c}\text { HUMAN } \\
\text { SERUM }\end{array} \\
1.970\end{array}$} \\
\hline Sulphanilamide & .. & .. & & & & & \\
\hline Sulphathiazole & . & . & 0.0502 & $0 \cdot 234$ & 5.90 & 0.0960 & 0.330 \\
\hline Sulphapyriđine & .. & .. & 0.0268 & 0.053 & $6 \cdot 65$ & 0.0486 & 0.0756 \\
\hline Sulphadiazine & .. & .. & 0.0077 & $0 \cdot 115$ & $5 \cdot 75$ & 0.0127 & $0 \cdot 161$ \\
\hline \multicolumn{2}{|c|}{ Sodium sulphathiazole } & $\cdots$ & $45 \cdot 0$ & - & $9 \cdot 65$ & $60 \cdot 0$ & - \\
\hline \multicolumn{2}{|c|}{ Sodium sulphapyridine } & .. & $52 \cdot 0$ & - & 10.85 & $80 \cdot 0$ & - \\
\hline \multicolumn{2}{|c|}{ Sodium sulphadiazine } & $\ldots$ & $50 \cdot 0$ & - & 9.90 & $65 \cdot 0$ & - \\
\hline
\end{tabular}

The solubilities are given as percentages $\mathrm{w} / \mathrm{w}$; and it may be noted that all of the sodium compounds coagulated the serum.

nitrogen and a sulphur atom in the ring. The melting point is $206-208^{\circ} \mathrm{C}$. (sulphathiazole melts at $200-203^{\circ} \mathrm{C}$.) and like sulphathiazole it is only slightly soluble in water. When tried on a series of eighty-eight male patients with gonorrhoeal urethritis, seventy-seven ( 87.5 per cent) were passed as cured after receiving 4 grammes of sulphathiazoline a day in divided doses for ten days, the average duration of symptoms being 3.2 days. The toxic manifestations encountered were much milder than those which are sometimes seen with sulphathiazole and it is for this reason that the authors believe it will prove to be a valuable addition to the drug treatment of gonorrhoea.

\section{Sulphamethylthiazole}

Although it has been advocated in the treatment of gonococcal infection, sulphamethylthiazole is not now advised because (1) it has a slower action than sulphathiazole, (2) it is not so efficient, and (3) there is a danger of its producing peripheral neuritis.

\section{Sulphapyridine}

Although sulphapyridine may not be the drug of choice in gonorrhoea it has been given and with good results when neither sulphathiazole nor sulphadiazine has been available. Here the principle of the "mass unit" dosage seems to hold a promising outlook. Analysis of 485 cases treated by Priest (1943) in a military hospital in Great Britain with a single dose of 10 grammes of sulphapyridine per person showed that 379 patients (78 per cent) had an average stay in hospital of 9.4 days, but 106 patients (21.8 per cent) required a further course and had an average of 23.7 days in hospital. The sulphapyridine was given in the form of twenty 0.5 gramme tablets crushed to powder and stirred into half a pint of milk and administered as soon as practicable after the patient entered the hospital. Each patient was also given three times a day a mixture containing potassium bicarbonate 10 grains, potassium citrate 20 grains, tincture of hyoscyamus 10 minims, with infusion of buchu to 1 fluid ounce. Of six different schemes of treatment with sulphapyridine tried by Laird (1942) in a series of 764 male patients in the Forces, all of whom were suffering from acute gonococcal anterior urethritis, the highest 
percentage of cures was achieved by giving the compound in doses of 1 gramme every four hours for four days (24 grammes), also using irrigation with 1 in 8,000 potassium permanganate solution at $105^{\circ} \mathrm{F}$. and maintaining a fluid intake of 7 pints daily. The " 8-7-7-6" treatment of gonorrhoeal infections has been claimed by Pappas (1942) to give a higher rate of cure with a shorter period in hospital than any other plan of sulphonamide therapy. Treatment consists of giving 8 grammes on the first, 7 grammes on each of the second and third, and 6 grammes on the fourth day, the patients remaining in hospital for an average of five days.

\section{Resistant strains}

The choice of sulphathiazole has not been based solely upon its efficiency in clearing the infection; more than one writer has stated that sulphanilamide and sulphapyridine are apt to induce toxic manifestations which are absent when sulphathiazole is administered, and there is also the possibility of sulphanilamide more readily producing drug-fast strains. There is, too, a danger in giving subtherapeutic doses of sulphonamides, for these may also produce strains of gonococcus resistant to the compound ; to quote Hanschell (1943), a " real and staring danger-the unhappy change of the sulphonamide beneficence into the curse of a widespread gonorrhoea no longer susceptible to sulphonamide cure". The problem of dealing with sulphonamide-resistant strains of gonococci has received a good deal of attention. Such strains have been shown by Petro (1.943) to be capable of transmission from one host to another and their development favoured by sub-therapeutic quantities of a sulphonamide. Of 956 patients suffering from acute gonorrhoea a group of fifty was taken as the clinical material for an investigation of sulphonamide resistance. In all, six patients failed to respond to sulphonamide treatment which consisted of giving either 16 or 24 grammes of sulphapyridine or sulphathiazole over a period which lasted for forty-four or ninety-two hours. It was found that a change to a different compound, for instance, from sulphapyridine to sulphathiazole or sulphadiazine, occasionally effected a cure. 'Whether the preliminary good results obtained by using a compound of sulphanilamide and urea will be confirmed it is too early to say, but the makers of this preparation have expressed confidence in its value in such cases.

\section{Prophylaxis}

A reference should be made to the results reported about the prophylactic use of sulphathiazole in preventing infection. Loveless and Denton (1943), in a preliminary report, state that by giving 2 grammes of sulphathiazole to approximately 1,200 negro troops before leaving camp on pass the incidence of venereal disease was much reduced, in fact there was " a phenomenal disappearance of gonorrhoea and chancroid". Actually the gonorrhoea rate dropped from 171 to 8 per 1,000 and the chancroid rate from 52 to 6 per 1,000 . Extensive trials have been made by surgeons in the United States Navy (Editorial, 1942). In one series of 1,000 possible exposures to infection, in which 2 grammes of the compound was given on the morning after the possible exposure and a similar dose later in the day, gonorrhoea developed in only one patient who received the full dose, in two patients receiving half the dose, and in seventy-nine patients to whom sulphathiazole was not given. In another series of 583 known exposures to contacts Arthur and Dermon (1943) gave 3 grammes immediately after breakfast, 2 grammes after dinner and 1 gramme after supper. It was found that whereas the rate of infection per 1,000 exposures to venereal disease for those not taking sulphathiazole after exposure to contacts was 109 , for those who received the prophylactic the rate of infection was only 30 per 1,000 exposures.

In chancroid infection, Greenblatt, Sanderson, Mortara and Kupperman (1943) at the University of Georgia School of Medicine have found that sulphathiazole given orally shortly before or after experimental inoculation prevented its development. The local application of sulphonamide preparations was also tried, successful results being obtained with sterile powders of sulphathiazole, sulphanilamide, 
sulphadiazine, and succinylsulphathiazole. The interesting information is given that the addition of sulphathiazole or one of the other sulphonamides to calomel ointment so as to produce a concentration of at least 20 to 25 per cent of the sulphonamide gave promise as an effective prophylactic agent, but further work is needed to ascertain the most effective ointment basis.

Recent work by Speert (1943) has shown that sulphathiazole and sulphadiazine diffuse readily across the placenta ; in fact after the mother has received 5 grammes of the sodium compound intravenously a therapeutically effective concentration of sulphathiazole is retained in the foetal blood for at least six hours, and in the case of sulphadiazine for a much longer period. It is suggested that when there is a gonococcal infection of the lower genital tract the administration of either sulphonamide in sufficient amount to establish an adequate concentration in the foetus is a prophylactic measure worth while taking.

The value of sulphonamide compounds in reducing the incidence of, or of ameliorating conditions associated with gonorrhoea has been confirmed by a number of venerologists. For example McElligott (1943) states that since it became a routine practice to treat gonorrhoea with the sulphonamides, epididymitis is less frequently seen. In gonococcal ophthalmia of infants Doble (1943) found that sulphathiazole 0.5 to 0.75 gramme daily, divided into six doses, and given with plenty of water was curative. In the routine treatment of 127 cases of balanitis and acquired phimosis of naval ratings seen by Jones (1942) over a period of two years, sulphanilamide, 3 grammes, was given daily (in three equal doses) and continued up to five days if necessary with good results. Large doses of sulphanilamide have been used successfully in the treatment of lymphogranuloma inguinale, as much as 100 grammes being given to one patient. The scheme of dosage observed by Law (1943) is to administer 2 grammes of the compound at four-hourly intervals for forty-eight hours followed by 1 gramme every four hours for seventy-two hours and finally 1 gramme at eight-hourly periods for forty-eight hours, the course being repeated after from five to seven days' rest. Better results are, however, claimed from anthiomaline (lithium antimony thiomalate), an organic compound containing 16 per cent of antimony.

Some cases of genital infection caused by gonorrhoea in the female which have not cleared up under the oral administration of sulphathiazole have benefited from the local use of this compound. Trials, reported by Roblee (1943) were made with a jelly having an acid reaction equivalent to a hydrogen ion concentration of $4 \cdot 5$. The jelly was made by mixing tragacanth 3 parts, acacia 2 parts, with glycerin 10 parts, and adding boric acid 3 parts, followed by 5 or 10 parts each of sulphanilamide and sulphathiazole dissolved in water with the aid of potassium hydroxide solution (18.8 per cent) and after making up to 100 parts adjusting the hydrogen ion concentration to 4.5 with acetic acid.

\section{REFERENCES}

Arthur, R. D., and Dermon, H. (1943) Amer. J. Syph., 27, 261.

Bell, P. H., and Roblin, R. O., Jun. (1942) J. Amer. chem. Soc., 64, 2905.

Clark, W. G., Strakosch, E. A., and Levitan, N. I. (1942) J. Lab. clin. Med., $28,188$. Doble, F. C. (1943) Med. Pr., 209, 221.

Domagk, G. (1935) Dtsch. med. Wschr., 61, 250.

Douglas, R. G., Davis, Iona F., and Shandorf, J. F. (1942) Amer. J. Obstet. Gynec., 44, 1026.

Editorial (1942) Vener. Dis. Inform., 23, 88.

Fildes, P. (1940) Lancet, 1, 955.

Gelmo, P. (1908) J. prakt. Chem. N.S., 77, 369.

Greenblatt, R. B., Sanderson, E. S., Mortara, F., and Kupperman, H. S. (1943) Amer. J. Syph., $27,30$.

Hanschell, H. M. (1943) Med. Pr., 210, 281.

Jefferiss, F. J. G., and McElligott, G. L. M. (1943) Lancet, 1, 65.

Jones, T. R. L. (1942) Brit. med. J., 1, 664.

Laird, S. M. (1942) Lancet, 1, 463.

Law, W. A. (1943) Lancet, 1, 300.

Leberman, P. R., and Alexander, R. (1943) Amer. J. Syph., $27,187$.

Loveless, J. A.; and Denton, W. (1943) J. Amer. med. Ass., 121, 827. 
McElligott, G. L. M. (1943) Brit. med. J., 1, 296.

Medical Research Council (1943) War Memorandum, No. 10.

Ministry of War Transport (1943) Notice to Ships' Masters, No. M.237.

Northey, E. H. (1943) Industr. Engng Chem., 35, 829.

Pappas, J. P. (1942) Milit. Surg., 90, 45.

Petro, J. (1943) Lancet, 1, 35.

Priest, W. H. D. (1943) J. R. Army med. Corps, 81, 139.

Roblee, M. A. (1943) Amer. J. Obstet. Gynec., 46, 400.

Speert, H. (1943) Amer. J. Obstet. Gynec., 45, 200.

La Towsky, L. W., Knight, F., Uhle, C. A. W., and Baker, R. B. (1942) J. Lab. clin. Med., 27, 1001.

Tréfouêl, J., and Tréfouêl, Mme. J., Nitti, F., and Bovet, D. (1935) C. R. Soc. Biol., 120, 756.

Wyss, O., Strandskov, Frede B., and Schmelkes, F. C. (1942) Science, 96, 236.

\title{
SPECIFIC REACTIONS OCCURRING IN THE TREATMENT OF LYMPHOGRANULOMA. VENEREUM WITH IMMUNE ANIMAL - SERUMS
}

\author{
By F. SAGHER, M.D. \\ Dermatological Department of the Rothschild-Hadassah University Hospital, Jerusalem
}

We have already reported elsewhere upon the results of the treatment of lymphogranuloma venereum with human convalescent serum. It has been pointed out that the use of this serum, in view of the results of experiments on thirty patients, could be regarded as a specific therapy for that condition. It was shown that the illness could be curtailed and that recurrences were not observed after the treatment had been carried out in the way suggested. Usually the serum was administered intramuscularly. In a later series of another twenty patients similar results were recorded when the serum was given intravenously but no acceleration of the healing process could be achieved by this method. Pursuing this line of treatment further, we tried to substitute for the human serum that of animals because, on the one hand, human convalescent serum is not always available and on the other it was desirable to have a method at hand which could also be used in the treatment of out-patients. Although the results of sulphonamide therapy applied to this disease are excellent and have been reported, specific therapy has not lost anything of its importance.

\section{Report of experiments}

A detailed account of our experiments, which met with a considerable degree of difficulty, is here published because it may supply an interesting contribution to the still rather unclarified problem of immunity in animals as well as in humans.

Human convalescent serum, whether given by the intramuscular or intravenous route, had not in any case produced ill effects apart from one patient who developed a gluteal abscess. To obtain convalescent serum from animals it is necessary to produce an infection in the animal and to obtain the serum during the period of healing or after disappearance of the symptoms. Monkeys or rabbits lend themselves to these experiments since only in animals of their size has the production of symptoms of lymphogranuloma venereum been effected. Neither guineapigs nor mice could be considered since the yield of antiserum is so small. As to other bigger animals it was not certain whether the disease could be transmitted to them, and we could not find any reference to this matter in the literature at our disposal. Since, for financial reasons, monkeys were out of the question, we decided to use rabbits and sheep although positive transmission to sheep has not previously been described.

The experiments were carried out as follows. Pus was injected into sheep and rabbits. It was obtained from a patient suffering from lymphogranuloma venereum and was taken on the same day on which the first injection was to be given to the animals. Since the virus is known to maintain its virulence for a 